\title{
Outcome of the Post-Operative Patients' Admissions in the Field of Resuscitation in Mali
}

\author{
Samaké Broulaye Massaoulé1, Beye Seydina Alioune², Tchaou Blaise Adélin³, Kassogué André1, \\ Tall FadimaKoureissi ${ }^{4}$, Keita Mohamed ${ }^{2}$
}

\author{
${ }^{1}$ Service of Anesthesia Resuscitation Academic Hospital, Gabriel Touré, Bamako, Mali \\ ${ }^{2}$ Service of Anesthesia Resuscitation Academic Hospital, Point G., Bamako, Mali \\ ${ }^{3}$ Service of Anesthesia, Resuscitation and Emergencies, Academic Hospitable Center and Department of the Bourgou/Alibori, \\ Parakou, Benin \\ ${ }^{4}$ Service of Anesthesia Resuscitation Academic Hospital, Kati, Bamako, Mali \\ Email: samakebroulaye@yahoo.fr
}

How to cite this paper: Massaoulé, S.B. Alioune, B.S., Adélin, T.B., André, K., FadimaKoureissi, T. and Mohamed, K. (2020) Outcome of the Post-Operative Patients' Admissions in the Field of Resuscitation in Mali. Open Journal of Anesthesiology, 10, 73-79.

https://doi.org/10.4236/ojanes.2020.103006

Received: December 21, 2019

Accepted: March 15, 2020

Published: March 18, 2020

Copyright (c) 2020 by author(s) and Scientific Research Publishing Inc. This work is licensed under the Creative Commons Attribution International License (CC BY 4.0).

http://creativecommons.org/licenses/by/4.0/

\begin{abstract}
Introduction: In spite of the use of the less and less invasive and the more and more effective techniques and the use of fast rehabilitation conditions of the patients in surgery, the post-operative complications (POC) stay the main reasons of admission in resuscitation service. Objective: To determine the post-operative outcome of the patients admitted in resuscitation. Patient and method: It was about a retrospective and transverse survey from June 2017 to May 2018 in the service of polyvalent resuscitation of the academic hospital center of Gabriel Touré. Have been included the patients operated for surgical or obstetric gynecology-pathologies admitted in resuscitation for post-operative complications established or potential precocious or late. The used statistical test was the $\mathrm{Chi}^{2}$ with $\mathrm{p}<0.05$ considered meaningful. The consent of the patients or parents was gotten. The survey didn't include a potentially dangerous act. Results: During the period, 514 patients have been admitted in resuscitation of which 140 cases of post-operatively represented $27.2 \%$ of the admissions. Under hospitalization $35.7 \%$ of patients have presented a complication. The middle age of patients was $37.72 \pm 20.9$ years. The sex ratio was 0.70 . The middle length of interventions was $122 \pm 83 \mathrm{~min}$ with extremes going from 20 to $434 \mathrm{~min}$. The predominant admission motive was hemodynamic instability. The delay of appearance intervening of the complications was 3 days in $94 \%$. The predominant complications were: respiratory (32\%), infectious (28\%) and Cardiovascular (20\%). The middle length of hospitalization was of $3.36 \pm 2.90$ days. The death rate was $15 \%$. The complications were related age, the class of Altemeïer, the ASA, and the perioperative undesirable events with $\mathrm{p}<0.05$. The deaths were related to the motives of admission and
\end{abstract}


the length of hospitalization with $\mathrm{p}<0.05$. Conclusion: The post-operative admissions in resuscitation are frequent including several factors of morbi-mortality. A better management per and postoperative of the patients operated would reduce the death rate. The profile mark is the one of a patient admitted for hemodynamic instability.

\section{Keywords}

Post-Operative Admission, Outcome, Resuscitation, Academic Hospital Gabriel Touré

\section{Introduction}

In the period perioperative the means of the resuscitation are used put in work to manage the patients needing a heavy surgical intervention, or those exposed threatened after an intervention to acute failure multi-visceral threatening the vital prognosis. In spite of the use of the less and less invasive and the more and more effective techniques and the use of fast rehabilitation conditions of the patients in surgery, the post-operative complications (POC) stay the main reasons of admission in resuscitation service. The infection represents the second reason of post-operative morbidity and mortality. The prognosis of the post-operatives complications passes by a precocious diagnosis and a multidisciplinary approach making intervene the anesthetist, the surgeon, the radiologist and the biologist [1]. In North America: Wanzel [2] 2 in Canada and Pittman-Waller [3] in USA have found respective a post operatives complications rates of $39 \%$ and $32 \%$ in 2000. In Europe: J.-C. Renggli [4] in Switzerland and Markus P. Mr. [5] in Germany found respectively in 2003 and in 2005 respective rates of $23.3 \%$ and $29.5 \%$. In Africa at the South of the Sahara the post-operative complications are dominated by the post operatives infections [6]. Dem TO [6] in Senegal and Mehinto [7] in Benin recorded in 2001 respective complications rates of $11.6 \%$ and $20.9 \%$ after appendectomy and intervention of Wertheim with a rate of post-operative infection respectively of $76 \%$ and $34.9 \%$. The admission of the patients operated in resuscitation denotes the established or potential gravity of the patient's state. We don't have any data on the types of patients admitted after surgery in our country from where the interest of this survey. The objective was to determine the outcome of the patients admitted in resuscitation.

\section{Patient and Method}

It was about a retrospective and transverse survey in the service of resuscitation of the academic hospital center Gabriel Touré of Bamako, from June 2017 to May 2018. The population of survey was constituted of the patients admitted in resuscitation. Were included the operated patients admitted in resuscitation for precocious or late post-operative complications. The studied qualitative values were: Sex, histories, operative indications, type of surgery according to the spe- 
cialty, context of the surgery (programmed or in emergency), anesthetic technique, undesirable events, surgical technique, type of post-operative complication, motive of admission, general state, results of para clinics exams and the evolution. The studied quantitative values were: age, the ASA class, lasted of intervention, the score of wakening of Aldrète, the delay of intervening of the complications and the length of hospitalization. All patients had benefitted from a rigorous surveillance under multipara metric monitor. The criteria of selection of the different types of complications are those of the literature [1] [8]-[13]. These complications are: renal, infectious, cardiovascular, digestive, anesthetics, neurological, respiratory hemorrhagic and of denutrition.

The data treatments have been made on the software IBM SPSS 19.0. The statistical test used for the comparison of the values was the Chi squared with a value of $p<0.05$ considered like meaningful. The consent of the patients or parents was gotten before the inclusion. The survey didn't include a potentially dangerous act.

\section{Results}

During the period data of 140 patients have been collected. This has represented $27.2 \%$ of the admissions in resuscitation, $35.7 \%$ have presented a complication. The sex ratio was 0.70 . The middle age was of $37.72 \pm 20.9$ years with the extremes of 6 to 83 years. At least a medical history was recovered in $17.1 \%$ of the patients and the surgical and anesthetic histories in $20.7 \%$. Forty percent of the patients were of class I of Altéméier. The predominant surgical indications were "the eclampsia, the peritonitis, the intestinal occlusion and the hemoperitoine" with respectively $32.9 \% ; 19.3 \% ; 10 \%$ and $4.3 \%$. The undesirable peroperative predominant event (EI) was hypotension in $29.3 \%$. Intervention was achieved in a context of emergency in $72.1 \%$ of the cases. General anesthesia was practiced in $97.1 \%$. The middle length of interventions was $122 \mathrm{~min} \pm 83 \mathrm{~min}$ with extremes of $20 \mathrm{~min}$. and $434 \mathrm{~min}$.

The instability hemodynamic and the change of the conscience were the predominant motives of admission with respectively $42.9 \%$ and $37.2 \%$ (Table 1 ). During the hospitalization the cardiovascular complications predominated with $56 \%$ (Table 2). The delay of intervening of the complications was 3 days in $94 \%$. The middle length of hospitalization was of $3.36 \pm 2.90$ days with extremes of 1 and 21 days. The mechanical ventilation was necessary at $17 \%$ of the patients and the use of the amino vaso activate in $16.4 \%$. A vascular replenishment was done in $27.9 \%$. The prevention of the thromboembolic pathology was efficient in $89.3 \%$. The death rate was of $15 \%$ of which $61.9 \%$ in a state of shock. The patients outcome was related to undesirable perioperative events with $p=0.02$ and $\mathrm{RR}=2.6[1.1-6]$. The undesirable events had occurred at $44.4 \%$ of the ASA class patients lower than 3 against $100 \%$ of those ASA class superior or equal to 3 with $\mathrm{p}=0.02$. They occurred in $33.7 \%$ of the Altemeier 1 class patients and 2 against $64.4 \%$ of the Altemeier 3 class patients and 4 with $p=0.001$. In $42 \%$ of 
Table 1. Motives of admission in resuscitation.

\begin{tabular}{ccc}
\hline Motive & $\mathrm{n}$ & $\%$ \\
\hline Conscience alteration & 52 & 37.2 \\
Cardio-respiratory failure & 3 & 2.1 \\
Respiratory distress & 9 & 6.4 \\
Hemodynamic instability & 60 & 42.9 \\
Delay of wakening & 16 & 11.4 \\
Total & 140 & 100 \\
\hline
\end{tabular}

Table 2. Complications after surgery.

\begin{tabular}{ccc}
\hline Complications & $\mathrm{N}=82$ & $\%$ \\
\hline Cardiovascular & 28 & $56 \%$ \\
Respiratory & 16 & $32 \%$ \\
Infectious & 14 & $28 \%$ \\
anesthetic & 9 & $18 \%$ \\
Hemorrhagic & 8 & $16 \%$ \\
Renal & 6 & $12 \%$ \\
Digestive & 1 & $2 \%$
\end{tabular}

surgery the length was less than 240 min. against $57.1 \%$ of surgery that lasted more than $240 \mathrm{~min}$. The post-operative complications were related to age $(\mathrm{p}<$ $0.05)$. The patients' outcome were related to the undesirable peroperative events with $\mathrm{p}=0.02$ and $\mathrm{RR}=2.6[1.1-6]$ (Table 3). More the interventions were long more the preoperative events occurred with $\mathrm{p}<0.05$. The mortality was related to the types of complications with $\mathrm{p}<0.05$; the hemorrhagic complications was more suppliers with a RR of 42 (Table 4 ).

\section{Discussion}

The admission in resuscitation after a surgery is a very frequent possibility. The prospective character of this survey permitted to make this report in our service of polyvalent resuscitation. The weak points of our survey were the bad storage of the files driving to the loss of some information and the precariousness constituting one handicap in the realization of some complementary exams. The frequency in our survey is more important than the one recovered in the literature [4] [5] [14] [15]. This difference seems to be explained by the choice of the inclusion criteria in the different sets. The young patients were more present in our series as in other African series [15] [16], but contrary in Europeans series [17]. These differences could be explained by the life expectancy that is low in Africa compare to Europe, and to the delay in the management of the patients in Africa. The women predominate in our serie contrary to the series of Assouto [14]. In this serie it was about only one service, in our serie all specialties were concerned. 
Table 3. Outcomes according to the preoperative undesirable events.

\begin{tabular}{cccc}
\hline \multirow{2}{*}{ Preoperative undesirable events } & \multicolumn{3}{c}{ Outcome } \\
\cline { 2 - 4 } & Death & Recovery & p-value \\
\hline Present & 14 & 47 & $\mathbf{p}=\mathbf{0 . 0 1 9}$ \\
Absent & 7 & 72 & $\mathbf{R R}=\mathbf{2 . 6}$ \\
Total & 21 & 119 & $\mathrm{DDL}=\mathbf{1}$ \\
\hline
\end{tabular}

Table 4. Outcome according to the types of complication.

\begin{tabular}{cccc}
\hline \multirow{2}{*}{ Complications Types } & \multicolumn{3}{c}{ Outcome } \\
\cline { 2 - 4 } Respiratory & Death & Recovery & p-value \\
Yes & 8 & 8 & $\mathrm{p}<0.001$ \\
No & 13 & 111 & $\mathrm{RR}=25.4$ \\
Infectious & & & $\mathrm{p}<0.001$ \\
Yes & 9 & 5 & $\mathrm{RR}=37.9$ \\
No & 12 & 114 & $\mathrm{p}<0.001$ \\
Cardiovascular & & & $\mathrm{RR}=42.9$ \\
Yes & 13 & 15 & \\
No & 8 & 104 & $\mathrm{p}<0.001$ \\
Renal & & & $\mathrm{RR}=17.9$ \\
Yes & 17 & 2 & $\mathrm{R}<0.001$ \\
No & 17 & 117 &
\end{tabular}

The eclampsia was the surgical indication the more recovered. This result defers the one of Assouto [14] where the peritonitis predominated. It can be explained by the fact that our survey has fine account of all post-operative admissions. The patients classified ASA1 are the more represented. Traoré [15] found that the majority of the patients was classified ASA 2 and 3. This difference would be explained by the predominance of the eclampsia. This obstetric pathology occurs the most often among young subjects without medico-surgical history. Interventions are achieved majoritary in a context of emergency that constitutes a factor of supplementary risk. The general anesthesia was the more practiced method. This technique of anesthesia is a factor of risk of post-operative complications by the vestigial effects of the anesthetic products on the respiratory, cardiac and neurological functions as the delay of wakening. Interventions are achieved in less than two hours for more of the half of the cases. The length of intervention is considered like a factor of risk of post-operative complications if it goes over: 
1 hour for a gynecological surgery 2 hours for endocrinologic surgery; 3 hours for a gastric, colic, ileale surgery, a nephrectomy; 4 hours for a neurosurgery and 5 hours for a cardiac surgery [18]. The predictive factors of undesirable event were the class of Altéméier, the ASA class and the length of intervention with $\mathrm{p}<$ 0.05 . More the interventions were long more the undesirable preoperative events were frequent. The arterial hypotension is the most frequent event. This report denotes the predominance of the cardiovascular complications found in our serie and also of the hemodynamic instability constituting one of the main motives of admission in resuscitation. The outcome of the patients in postoperative period was related to the undesirable preoperative event with an important relative risk about 3. The state of shock predominates among the reasons of death in our series as in the series of Assouto [14] where a predominance of the shock states exists in $42.5 \%$, respiratory complications in $17.5 \%$, of the infectious complications in $16.2 \%$ and the renal insufficiency in $3.8 \%$. These results could be explained by the inaccessibility to the care, the morbid state of the patients in the admission, the delay of the patients care, the septic environment of the hospitalization rooms and the maladjusted use of the antibiotics. The relative risk of death according to the different types of complications is very variable. It is of 42 for the cardiovascular complications against 25 for the respiratory complications. It could be explained by the fact that tissular hypoperfusion can be the bed of other complications such as respiratory and renal complications. A pulmonary hypoperfusion will generate a hypoxemia conducting to the pulmonary infectious whose prognosis is very often pejorative in intensive care. Also an acute renal insufficiency can evolve toward a chronic renal insufficiency.

\section{Conclusion}

The post-operative admission is a frequent possibility. The profile of the post-operative patients of our structure is the type of a female young patient, presenting established or potential complications and neurological hemodynamic. A perioperative adequate management in a perfect organization will permit to reduce the post-operative complications.

\section{Conflicts of Interest}

The authors declare no conflicts of interest regarding the publication of this paper.

\section{References}

[1] Gouin, F., Guidon, C., Bonnet, M. and Grillon, P. (2004) Complications postopératoires précoces et leur prévention. Traité d'anesthésie générale. édition, Arnette Groupe Liaison S.A, Partie V, Chap. 11, Paris, 2-36.

[2] Wanzel, K.R., Jamieson, C.G. and Bohmen, J.M. (2000) Complications on a General Surgery Service: Incidence and Reporting. Canadian Journal of Surgery, 43, 113-117. 
[3] Pittman-Waller, V.A., Myers, J.G., Stewart, R.M., Dent, D.L., Plage, C.P., Gray, G.A., Pruitt Ba, J.R. and Root, H.D. (2000) Appendicitis: Why So Complicated? Analysis of 5755 Consecutive Appendicectomie. American Surgery, 66, 548-554.

[4] Renggli, J.C., Chevre, F., Delgadillo, X., Lekeufack, J.B. and Merlini, M. (2003) Analyse prospective des complications post opératoires (CPO) fondée sur un collectif de 10066 patients. Annale de Chirurgie, 128, 488-518.

[5] Markus, P.M., Marell, J., Leister, I., Horstmann, O., Brinker, J. and Becker, H. (2005) Predicting Post-Operative Morbidity by Clinical Assessment. British Journal of Surgery, 92, 101-106. https://doi.org/10.1002/bjs.4608

[6] Dem, A., Kasse, A.A., Diop, M., Fall-Gaye, M.C., Diop, P.S., Dotou, C., Ciss, M.L. and Touré, P. (2001) Colpohystérectomies élargies avec lymphadénectomie pour cancer du col utérin à l'institut du cancer de Dakar: À propos de 412 cas. Dakar Médical, 46, 39-42.

[7] Mehinto, D.K.I., Olory-Togbe, J.L.I. and Padonou, N.I. (2004) Les complications d'appendicectomies pour appendicite aiguent chez l'adulte au centre National Hospitalier et Universitaire de Cotonou. Médecine d Afrique Noire, 51, 361-365.

[8] Canaud, B. (2005) Insuffisance rénale aigue péri opératoire: Définition, critères diagnostiques et pronostiques. Annales Françaises d Anesthésie et de Réanimation, 24, 126-133. https://doi.org/10.1016/j.annfar.2004.11.016

[9] Telion, C. and Carli, P. (2001) Etat de choc et remplissage. Société française d'Anesthésie-Réanimation, conférence d'actualisation. Edition Masson, Paris, 120-131.

[10] Audibert, G., Gette, S. and Bauman, A. (2009) Accidents vasculaires cérébraux péri opératoires. Société Française d'Anesthésie-Réanimation, conférence d'actualisation. Edition, Masson, Paris, 2-13.

[11] Kitzi, M. (1991) Risque infectieux en chirurgie, antibioprophylaxie: Nouvelles stratégies. Annales Françaises de Chirurgie, 9, 15-21.

[12] Stephan, F. (2002) Complications postopératoires de la chirurgie pulmonaire. Annales Françaises d' Anesthésie et de Réanimation, 11, 40-48. https://doi.org/10.1016/S1624-0693(01)00202-X

[13] Rezaguia, S. and Jayr, C. (1996) Prévention des complications respiratoires après chirurgie abdominale. Annales Françaises d Anesthésie et de Réanimation, 15, 623-646. https://doi.org/10.1016/0750-7658(96)82128-9

[14] Assouto, P., Tchaou, B., Kangni, N., Padonou, J.L., Lokossou, T., Djiconkpode, I. and Aguemon, A.R. (2009) Evolution post-opératoire précoce en chirurgie digestive en milieu tropical. Médecine Tropicale, 69, 477-479.

[15] Traoré, A., Diakité, I., Dembélé, B.T., Togo, A., Kanté, L., Coulibaly, Y., Keïta, M., Diango, D.M., Diallo, A. and Diallo, G. (2011) Complications post opératoires précoces en chirurgie abdominale au CHU Gabriel Touré. Médecine d Afrique Noire, 5801, 31-35.

[16] Ndayisaba, G., Bazira, L., Gahongano, G., Hitimana, A. and Karayuba, R. (1992) Bilan des complications infectieuses en chirurgie générale: Analyse d'une série de 2218 interventions. Médecine d Afrique Noire, 39, 571-573.

[17] Proske, J.M., Raue, W., Neudecker, J., Muller, J.M. and Schwenk, W. (2005) Réhabilitation rapide en chirurgie colique: Résultats d'une étude prospective. Annales Françaises de Chirurgie, 130, 152-156. https://doi.org/10.1016/j.anchir.2004.12.012

[18] Kitzis, I.M. (1991) Risque infectieux en chirurgie, antibioprophylaxie: Nouvelles stratégies. Annales Françaises de Chirurgie, 9, 15-21. 